\title{
Morphosyntactic variation in Modern Greek dialects
}

An introduction

\author{
Marika Lekakou \\ University of Ioannina \\ mlekakou@cc.uoi.gr
}

\begin{abstract}
This introduction lays out the issues in the study of morphosyntactic variation in Modern Greek dialects and summarizes the contents of the papers included herein.
\end{abstract}

\section{Keywords}

Greek - dialectology - syntax - morphosyntax - microvariation

The current issue contains a selection of the papers presented at the workshop on the morphosyntax of Modern Greek dialects, which was organized by Arhonto Terzi and myself in September 2015 and was hosted within the 12th International Conference of Greek Linguistics (ICGL 12) at the Freie Universität Berlin. In addition to the four papers published here, the workshop program also featured the following presentations:

- Yoryia Agouraki, Accommodating the 'recalcitrant' data of Cypriot Greek clitic placement

- Marika Lekakou \& Petros Karatsareas, The two faces of Modern Greek determiner spreading

- Cristina Guardiano \& Melita Stavrou, Adjective-Noun combinations in the Greek of Italy: polydefiniteness revisited

- Nikos Liosis \& Eirini Kriki, AVCs \& clitic placement in Tsakonian

- Stergios Chatzikyriakidis, Dimitris Michelioudakis \& Giorgos Spathas, Promiscuous by-phrases in Greveniotika Greek

(C) MARIKA LEKAKOU, 2017 | DOI: $10.1163 / 15699846-01702003$

This is an open access article distributed under the terms of the prevailing CC-BY-NC license 
Forvarious reasons, these papers could not be included in the current selection. Publications related to some of these papers are Guardiano \& Stavrou (2014), Lekakou \& Karatsareas (2016), Liosis (2017).

Before presenting in summary the four papers that have been included in this special issue, in the following section I spell out the rationale behind submitting a proposal for a workshop dedicated to the morphosyntax of Modern Greek dialects, and behind the publication of a selection of the papers presented therein.

Despite the various difficulties that dialectological research in the Greek language area presents (see Trudgill 2003), the interest in dialects has been vivid within the community of Greek scholars and language specialists from very early on. The interest has taken both a more traditional (historical, dialectological or other) perspective - the earliest references include Hatzidakis (1892) and Dawkins (1916) — and, more recently, theoretical viewpoints (see, e.g., Newton 1972). The collections of articles in Christidis (1999, 2000) and references therein (see also Kontosopoulos 2001) provide an overview of existing Modern Greek dialects. An up-to-date and comprehensive description of particular dialects, edited by Christos Tzitzilis, is forthcoming. ${ }^{1}$

In more recent years, and in line with worldwide tendencies (see below), dialectological research has witnessed a noticeable renewed interest. Alongside the work carried out at the Research Center for Modern Greek Dialects of the Academy of Athens, within the framework of the Historical Dictionary of the Greek Language (http://www.academyofathens.gr/en/kentro/ilne/centre), intensive research has taken place at the Laboratory of Modern Greek Dialects of the University of Patras (http://lmgd.philology.upatras.gr/index.php/en/), with a pronounced focus on lexis, phonetics, and especially morphology. The interest is reflected in the various projects that have been completed or are currently underway, there and elsewhere, investigating particular aspects of the grammar of Modern Greek dialects; as an indication, see for instance Vocalect, http://www.vocalect.eu/?lang=en, hosted at the University of Ioan-

1 One of the major persisting lacunae, underlined in Trudgill (op.cit.), is the lack of a dialect atlas for the Greek language area (with the notable exception of Crete, on which see Kontosopoulos 1988), and the related lack of a classification for Modern Greek dialects; see Trudgill (op.cit.) for discussion, and an explicit contribution to the latter point. 
nina, AMiGre, http://amigre.cs.teiath.gr/en/index.php, hosted at the University of Patras, and a project on Romeyka http://www.romeyka.org/the-romeyka -project/rediscovering-romeyka, hosted at the University of Cambridge. A biennial conference dedicated to Modern Greek Dialects and Linguistic Theory (MGDLT) regularly attracts interested scholars from within and outside Greece, and publishes proceedings which recently have also become available online (http://resmicte.lis.upatras.gr/index.php/mgdlt).

Even though the interest in dialectal variation on the part of language specialists has been evidently constant, the level of (morpho)syntax has largely been neglected, as observed also by Tzitzilis (2000). This is by no means a peculiarity exclusive to the Greek community. It has been often observed, within different linguistic communities, that syntax is invariably overlooked in dialectal research. Brandner (2012:118) discusses this point explicitly, and suggests the following list of reasons for the lack of attention paid, until recently, to the level of (morpho)syntax in dialectological studies:

- Syntax has an inherent complexity that exceeds that of phonology and the lexicon, simply as a matter of combinatorial possibilities; syntactic constructions can not be as easily 'listed' as, e.g., lexical items, the phonological inventory, and morphological paradigms.

- The elicitation of syntactic data must be based on theoretical considerations. Every satisfying syntactic description must also make use of grammaticality judgments, which requires a careful and theoretically motivated design of a questionnaire.

- Syntax was not considered to be a worthwhile object of study since the syntactic differences between the dialects seemed to be negligible (or non-existent at all).

- Finally, rooted in the traditional attitude towards dialects as the language of uneducated speakers, syntactic research was often impeded by prejudices like "the syntax of dialect $\mathrm{x}$ is simple and incomplete, e.g., less subordination, simpler case systems etc."

Despite these difficulties, to which I return presently, the relevance of dialectal variation has been widely acknowledged by theoretical syntacticians at least since Kayne (1996). Kayne pointed out one of the major benefits of adopting the microcomparative method, namely of investigating dialectal variation at the level of syntax, also known as syntactic microvariation: like a well-designed experiment, the examination of closely-related varieties provides us with a precise and controlled method of studying grammatical variation. In other words, syntactic microvariation is the closest syntacticians can get to a controlled 
experiment, through which the effects are revealed of altering as few syntactic variants as possible. As elaborated on by Barbiers (2009), the microcomparative method addresses questions regarding the limits and locus of (morpho)syntactic variation, which are central to syntactic theory. Which aspects of grammatical systems vary, and what are the bounds of variation? Is variation in the atoms of syntax (lexical items conceived of as bundles of abstract features); is it syntax itself, i.e. the operations whereby the atoms of syntax are combined; or is it the interfaces (LF and PF, including morphology, on the assumption of morphology as operating post-syntactically)? As Barbiers underscores, according to a strictly minimalist agenda (Chomsky 1995), microvariation results ultimately from properties of the lexical items and their feature specification. The syntactic modes of combination do not differ cross-linguistically. ${ }^{2}$

Furthermore, as Koeneman \& Lekakou (2007) point out, the microcomparative method entails an intensive interaction between theory and data. On the one hand, as analyses and correlations have, more often than not, been proposed on the basis of standard varieties, the dialectal data provide a new empirical basis on which to test the validity of these proposals. Microcomparative research enables us to potentially discover new correlations, which may have been obscured by the emphasis on standard varieties. ${ }^{3}$ On the other hand - and this relates to the second point raised by Brandner above-, it is only through formulating a particular hypothesis about what the empirical picture may look like that one can collect the most relevant and revealing data, data which may have otherwise been ignored; thus, data collection can be most beneficial if it is theoretically informed. Ultimately, a more complete understanding of the nature of the studied phenomena, of linguistic variation and

2 This is referred to by Baker (2008: 253) as the Borer-Chomsky conjecture, stated as in (i): The Borer-Chomsky Conjecture (BCC)

All parameters of variation are attributable to differences in the features of particular items (e.g., the functional heads) in the lexicon.

Baker (op.cit.) argues that the locus of syntactic variation is not exhausted by (i). Syntactic variation does not, in other words, always reduce to lexical variation. See Baker's paper for the argumentation as to why conducting macro-parametric, in addition to micro-parametric research, is necessary, also from the perspective of determining the answer to this question.

3 This extends to phenomena only or mainly attested in dialects, such as for instance the pervasiveness of doubling phenomena in dialects, as examined in the collection of papers in Barbiers et al. (2008b). Note that the tendency for certain phenomena to mainly occur in dialects in itself generates a new set of research questions. 
of language in general can be had if one does not confine one's attention to standard varieties. ${ }^{4}$

Reasons such as the above have prompted a lively and sustained interest in the investigation of the (morpho)syntactic properties of dialectal (or, more generally, non-standard) varieties. This is evidenced by, among other things, the large number of research projects across Europe (and beyond) which focus exclusively on the (morpho)syntax of dialects. The syntactic atlas of Northern Italian dialects (see Benincà \& Poletto 2007) and the syntactic atlas of Dutch dialects (Barbiers et al. 2005, 2008a) can rightly be considered as pioneering in this respect. Among other things, they may deliver printed geographical atlases that map syntactic variation, or in some cases even online searchable databases; see for instance the Dynamic Syntactic Atlas of the Dutch dialects, http://www.meertens.knaw.nl/sand/zoeken/index.php and the Nordic Dialect Corpus and Syntax Database, http://www.tekstlab.uio.no/nota/ scandiasyn/index.html. ${ }^{5}$ Doctoral dissertations and theoretical analyses of particular phenomena have also been made available through projects such as the above. The interested reader is referred to the documentation made through the EDiSyn project (http://www.dialectsyntax.org/wiki/Main_Page) for an overview.

As a result of such research, there is by now substantial evidence supporting the fact that the latter two prejudices mentioned in the quote by Brandner above are nothing more than prejudices: (morpho)syntactic variation is much more widespread than previously thought, and a valid object of scientific inquiry. Regarding the first two points raised by Brandner, which relate to the observable difficulties in investigating the syntactic properties of dialects, the challenges have often meant scientific progress here too; a fruitful collaboration has in many cases developed between language specialists of different persuasions, such as formal syntacticians, typologists, historical linguists, traditional dialectologists and sociolinguists. On the basis of this kind of collaboration, and because of the challenges of collecting dialectal data, it has become possible and necessary for theoretical linguists to be more rigorous in their

4 The insights dialects can offer to diachronic research are, of course, another point which is worth highlighting. See Joseph (1983) for an early discussion of the loss of infinitives in the diachrony of Greek, and see Baldissera (2013) for an examination of its retention in Griko, the Modern Greek dialect of Puglia. Another recent example of the fruitful interaction between diachronic and dialectal research, on (the loss of) nominal morphology in Cappadocian Greek, is Karatsareas (2013).

5 For an example from Modern Greek dialects see the searchable database in Lekakou et al. (2013), http://griko.project.uoi.gr/. 
methodology (cf. Brandner op. cit). Cornips \& Poletto (2004) offer an extensive discussion and comparison of the various different methods that have been employed in dialect syntax projects. Furthermore, as Barbiers \& Cornips (2002:3) highlight, "a dialect does not exist in isolation, it is in a constant interaction with one or more standard languages and with other dialects". Therefore, studying dialects can shed light on questions of language contact and contactinduced change (Thomason \& Kaufman 1988, Heine \& Kuteva 2005, among many others). Indeed, a lot of recent research on dialects approaches the topic (also) from the perspective of language contact.

Within the Greek linguistic community, no large-scale dialect syntax project of the kind that has been undertaken in e.g. Northern Italy or the Netherlands and Belgium has been carried out. However, that is not to say that theoretical linguists have ignored (morpho)syntactic microvariation. The overview by Ralli (2006) attests to the wealth and diversity of (morpho)syntactic phenomena occurring in Modern Greek dialects, as documented by the limited relevant literature. Since Ralli's overview paper was published, several articles or $\mathrm{PhD}$ dissertations exclusively dedicated to aspects of the (morpho)syntax of dialects have been produced, more than can be done justice to in the confines of this introduction; to mention only a few, see Roussou (2009), Chatzikyriakidis (2010), Baldissera (2013), Guardiano \& Stavrou (2014), Lekakou \& Karatsareas (2016), Lekakou \& Quer (2016), and numerous publications by Ioanna Sitaridou (and colleagues), including Sitaridou (2014) and Michelioudakis \& Sitaridou (2016); see also references to the individual papers in this issue.

The workshop on the morphosyntax of Modern Greek dialects organized within ICGL 12 in 2015 aimed at bringing together those researchers working on the topic, to raise awareness of the attested variation, to report it, and to highlight its contribution to (morpho)syntactic theory. Similar goals have been set for the collection of papers presented here.

The papers in this issue focus on dialects that are (or were originally) spoken in the extremities of the Greek language are, namely Pharasiot (a member of the Asia Minor Greek dialect family, which includes Pontic Greek and Cappadocian Greek), Calabrian Greek or Greko (a member of the Italo-Greek dialect family, which also includes Griko, the variety spoken in Salento), and Cypriot Greek. The empirical domains of DP-structure, IP-structure and CP-structure are addressed. All papers assume a microcomparative approach. Basing themselves on existing empirical observations, the authors of the papers all go sev- 
eral steps further, empirically and/or theoretically, and they do so by putting forward explicit theoretical proposals whose predictions are tested, thereby yielding new empirical data.

In the remainder of this introduction, I offer a brief summary of each contribution.

\subsection{Metin Bağrıaçı: "Representing discourse in clausal syntax: The ki particle in Pharasiot Greek"}

The topic of the paper is the particle $k i$ as it occurs in the Modern Greek dialect of Pharasa (Asia Minor Greek). Bağrıaçık examines the occurrence of $k i$ in the following seemingly unrelated environments: quotative constructions, complements to assertive predicates, so-called causative and see-constructions, $k i$ in combination with epistemic adverbs, and in clause-final position in so-called emphatic clauses. The author maintains a uniform approach to ki in all these constructions, and provides syntactic derivations for each of these constructions.

In line with recent literature on the syntactic realization of discourse-related phenomena, Bağnıaçı proposes that $k i$ is a device displaying the strength of the speaker's belief in her assertion (what is dubbed "epistemic vigilance"). More specifically, Bağraaçı couches his analysis within the cartographic approach (Rizzi 1997 and subsequent work), thus assuming a highly articulated left periphery of the clause. Bağrnaçık proposes to expand the left periphery so as to include the position hosting ki, namely the head of the Speech Act Phrase (SAP). This SAP occurs above the highest CP, ForceP. Bağraçık observes that, in the presence of $k i$, epistemic adverbs receive only one of the interpretations otherwise available to them, namely a speaker-oriented one. This is in line with ki realizing the head of SAP. Endowed with pragmatic (sentience) features relating to the speaker, $k i\left(=\mathrm{SA}^{0}\right)$ attracts epistemic adverbs to its specifier, in order to have the relevant features checked.

Extending the basics of this analysis to the rest of the environments where ki occurs, Bağraçlk argues that in see-constructions and in causative constructions, what looks like the first conjunct (i.e. the clause preceding $k i$ ) is actually merged as an adverbial clause in Spec, SAP. In other words, what looks like co-ordination in fact involves a single clause, whose left periphery hosts the linearly first clause. As for complements to assertion predicates and quotative constructions, Bağraçlk argues that it is the matrix clause (ForceP) that is attracted to Spec, SAP; what looks like the complement or the quote in fact occupies an adjunct position. The same movement of ForceP to Spec, SAP occurs in emphatic clauses, which differ from the above two cases only in that no apparent complement occurs. 
The analysis provides a uniform approach to $k i$, and a unification of all contexts in which it surfaces. Furthermore, the paper addresses the issues of (apparent) optionality and 'emphatic' uses of particular linguistic devices. Both these issues come up quite frequently in examinations of dialectal morphosyntax (see, e.g., the contributions in Barbiers et al. 2008b). Bağnaçık's careful examination of contexts where $k i$ seems to be optional reveals subtle semantic effects, with explicitly discussed structural correlates; his proposal gives concrete content to the otherwise rather vague notion of emphasis.

\subsection{Marios Mavrogiorgos: "Decomposing EPP effects in Greek enclisis"}

Mavrogiorgos' paper discusses the order of (finite) verb and clitic(s) in Cypriot Greek (CG) and Standard Greek (SG), and proposes a novel account, which relates enclisis in CG to satisfaction of the EPP (Extended Projection Principle, Chomsky 1981 and much subsequent literature). The starting point of the paper is a well-documented generalization concerning the distribution of enclisis and proclisis in the varieties under discussion. In SG, proclisis is obligatory with finite verbs, and enclisis is obligatory with non-finite verbs, namely gerunds and imperatives. The distribution of enclisis and proclisis in SG thus relates exclusively to the finiteness of the verb (where finiteness is defined in terms of lack of and/or restricted person specification on the verb, cf. Joseph 1983: Chp. 2, Mavrogiorgos 2010). In CG, on the other hand, the choice between enclisis and proclisis is more intricate: whereas, like in SG, clitics follow non-finite verbs (i.e. imperatives and gerunds), with finite verbs what seems to be crucial are properties of the left periphery of the clause; enclisis is the default, unless some preverbal constituent of a particular type c-commands the cluster of clitic and finite verb.

Assuming, like Bağraçık, a highly articulated left periphery, in line with Rizzi (1997) and Roussou (2000) in particular for SG, Mavrogiorgos identifies as crucial the local domain above TP and below the Topic Phrase. He proposes that a head $\mathrm{H}$, defined structurally but not in terms of feature-content, occurs within this domain, c-selecting TP and imposing morphosyntactic and phonological requirements. The former entail merger of a constituent (X or XP) in $\mathrm{H}$; the latter enforce spell-out of the head or the specifier of $\mathrm{H}$. In the presence of an element satisfying these requirements of $\mathrm{H}$, the realization of the verb within the relevant domain is blocked, resulting in proclisis. Enclisis is triggered when the verb itself merges in H. Microvariation between SG and CG resides not in the syntactic mode of combination, but in the varying properties of the head $\mathrm{H}$ in the two varieties (cf. the Borer-Chomsky conjecture mentioned in fn. 2).

Apart from contributing a novel account for facts that have been welldocumented in the relevant literature (though see section 3.2 for a new empir- 
ical observation), the paper also contributes to the ongoing discussion on the nature of the EPP, taking a clear stand on the necessity of viewing the latter as having PF-related, in addition to morphosyntactic, requirements.

\subsection{Jason Merchant \& Natalia Pavlou: "The morphosyntax of the periphrastic future under negation in Cypriot Greek"}

The interplay between morphosyntactic theory and dialectal data is also evident in the paper by Merchant and Pavlou, which discusses, broadly speaking, the expression of futurity in Cypriot Greek (CG). The paper makes a clear empirical contribution: whereas existing literature denies the existence in CG of the SG modal/future particle tha, the authors of the paper argue that tha also exists in CG, albeit in restricted contexts. In particular, the empirical claim is that tha exists in CG in the context of clause-mate negation. In declarative clauses, what surfaces as the expression of futurity is the periphrasis en $n a+$ finite verb; to negate that, the only option hitherto recognized in the literature has been to insert negation $(\mathrm{min}$ ) below $n a$; the combination of negation $(d) e n$ followed by en na is ungrammatical (though see below). Merchant \& Pavlou argue that in this case, what is in fact also possible for speakers of CG is (d)en tha + finite verb, i.e. the version with the SG modal particle tha.

The authors argue for a bi-clausal analysis of the CG periphrastic future, according to which the copula en heads a VP and selects a CP headed by $n a$. They further propose an analysis within the framework of Distributed Morphology, where tha and en na are essentially allomorphs, i.e. elements realizing the same syntactic nodes, albeit in different syntactic contexts: in the environment of local negation, tha is inserted, otherwise the elements en and $n a$ are inserted. What is special, in other words, about the Vocabulary Insertion entry for tha, is that it specifies that tha spells out multiple syntactic nodes (three, or two, depending on how Tense in the copular clause is treated). Thus, following a number of authors, Merchant \& Pavlou assume a theory that allows vocabulary items to spell out multiple nodes; in other words, Vocabulary Insertion may target so-called spans. Merchant \& Pavlou show that tha shows up only when these multiple nodes are adjacent to each other and stand in a selection relation, and propose a definition of spans that reflects this. According to their treatment, micro-variation between SG and CG is strictly not syntactic, but lies in the nature of the different vocabulary items.

On the basis of the proposed analysis, a number of predictions are tested, which deliver new data from CG. One of the empirical findings is that the combination of negation $(d) e n$ followed by en $n a$ is grammatical after all (cf. example (33) of the paper); even though the question of the distribution of this sequence is not addressed, it becomes clear that the expression of futurity in 
CG merits further investigation. This conclusion is also reached on the basis of the final sections of the paper, which briefly address another occurrence of tha in CG, as well as an alternative though related future periphrastic expression in the variety.

\subsection{Georg Höhn, Giuseppina Silvestri \& Maria Olimpia Squillaci: "Greek and Romance unagreement in Calabria"}

The paper is concerned with variation in nominal structure between ItaloGreek and Italo-Romance varieties in Southern Italy, which the authors relate to effects of language contact among the varieties spoken in the area. Concretely, the topic of the paper is the phenomenon of so-called unagreement, whereby a definite subject DP combines with a verbal form marked for 1st or 2nd person; this seems to be an unexpected instance of failure of the subject to agree (in particular, in person) with the verb, whence the term "unagreement". Following Höhn (2016), the authors maintain that what enables such structures to exist, in the null subject languages that allow them, is the fact in those languages, person is encoded in a head distinct from D, namely Person, which selects for DP. Standard Greek (SG) is such a language. Pro-drop is viewed as the phonologically null realization of Person; when Person is null, if the rest of the nominal structure is realized phonologically, it will feature the remaining DP. By contrast, in, for instance, Italian, D includes specification for person and no separate PersonP is projected; this makes it impossible for Person but not D to receive null realization. This captures the unavailability of unagreement in Italian.

Following Höhn (2016) and others, the authors maintain that a correlation exists between the availability of unagreement and the realization of the definite article in so-called adnominal pronoun constructions (APCs), i.e. nominal constructions featuring a 1st or 2nd person pronoun followed by a definite DP (cf. we linguists). As the authors show, the correlation holds for a number of languages, including Italian and SG, as well as Calabrian Greek (or Greco), the Modern Greek dialect spoken in Calabria. In this respect then, no microvariation between SG and Greco is attested. It is the Italo-Romance varieties spoken in Calabria that present a problem for the suggested correlation. Unlike Italian, Calabrian dialects have unagreement: they allow for an apparent mismatch in person between the verb (which can be 1st or and person) and its definite DP subject-like SG and Greco. However, unlike SG and Greco, Calabrian dialects disallow the realization of the definite article in APCs, thus patterning with Italian. The authors propose to maintain the correlation between the availability of unagreement and the realization of the definite article in APCS, and provide a solution to the problem presented by Calabrian dialects which highlights 
the relevance of contact in the emergence of hybrid grammars. Concretely, the authors suggest that the same structure proposed for SG-style nominals, where Person is distinct from D, exists in Calabrian dialects. Supporting evidence, which attests to the robustness of the unagreement phenomenon, comes from quantificational and wh-unagreement data, which the authors bring to the fore for all varieties discussed in the paper, thus enriching the discussion on unagreement in general. The fact that APCs feature no definite article in Calabrian is considered a "surface-oriented constraint": due to contact with Italian, $\mathrm{D}$ receives null spell-out in the context of an overt Person head in the relevant dialects. Thus, the acquisitional cue for the postulation of a Person-D split comes from unagreement. The authors observe that, whereas in SG and Greco APCs are regularly available, to their Calabrian informants they sound highly marked, compared to unagreement constructions. The APC data would then be peripheral, if not entirely absent, as primary linguistic data, with a limited (if any) effect on acquisition.

In the final part of the paper, the authors attribute unagreement in the Italo-Romance dialects to contact with Greek. The influence of Greek on the Romance varieties in the area has been argued for in a number of domains, including morphosyntax (see Rohlfs 1924 and subsequent work, and Ledgeway 2013 for a recent overview). The authors offer a separate discussion for southern and northern Calabrian dialects, to support the hypothesis that unagreement is yet another contact-induced feature, attesting to the intense contact between Italo-Greek and Italo-Romance in the area.

\section{3}

Envoi

I would like to thank all authors for their collaboration throughout all stages of the publication process, as well as the editors of the journal for their interest and faith in this particular project. Special thanks go to the reviewers, whose comments led to substantial improvement of all papers; in alphabetical order they are: Elena Anagnostopoulou, Christina Guardiano, Marit Julien, Theodore Markopoulos, Ad Neeleman, Vasilis Spyropoulos, Arxonto Terzi, and George Tsoulas.

\section{References}

Baker, M. (2008). The macroparameter in a microparametric world. In T. Biberauer (ed.) The limits of syntactic variation. Amsterdam: John Benjamins, 351-374. 
Baldissera, V. (2013). Il dialetto grico del Salento: elementi balcanici e contatto linguistico. Venezia: University of Venice dissertation.

Barbiers, S. (2009). Locus and limits of syntactic microvariation. Lingua 119: 1607-1623. Barbiers, S. \& L. Cornips (2002). Introduction to Syntactic Microvariation. In S. Barbiers, L. Cornips, \& S. van der Kleij (eds.). Syntactic Microvariation. Amsterdam: Meertens Instituut. http://www.meertens.knaw.nl/books/synmic/introduction.pdf

Barbiers, S., H. Bennis, G. de Vogelaer, M. Devos \& M. van der Ham (2005). Syntactische Atlas van de Nederlandse Dialecten / Syntactic Atlas of the Dutch Dialects Volume I. Amsterdam: Amsterdam University Press.

Barbiers, S., J. van der Auwera, H. Bennis, E. Boef, G. De Vogelaer \& M. van der Ham (2008). Syntactische Atlas van de Nederlandse Dialecten Deel II / Syntactic Atlas of the Dutch Dialects Volume II. Amsterdam: Amsterdam University Press.

Barbiers, S., O. Koeneman, M. Lekakou \& M. van der Ham. (2008). Microvariation in syntactic doubling (Vol. 36. Syntax \& Semantics). Bingley: Emerald.

Benincà, P. \& C. Poletto (2007). The ASIS enterprise: a view on the construction of a syntactic atlas for the Northern Italian dialects. Nordlyd 34: $35^{-52}$.

Brandner, E. (2012). Syntactic Microvariation. Language and Linguistics Compass 6:113130.

Chatzikyriakidis, S. (2010). Clitics in four Dialects of Modern Greek: A Dynamic Account. PhD Dissertation. King's College, University of London.

Chomsky, N. (1981). Lectures on Government and Binding. Dordrecht: Foris.

Chomsky, N., 1995. The Minimalist Program. Cambridge, MA: MIT Press.

Christidis, A.F. (ed.) (1999). Dialect Enclaves of the Greek Language. Athens: Greek Ministry of Education and Religious Affairs \& Centre for the Greek Language.

Christidis, A.F. (ed). (200o). The Greek Language and its Dialects. Athens: Greek Ministry of Education and Religious Affairs \& Centre for the Greek Language.

Cornips, L. \& C. Poletto. (2004). Standardisation of syntactic elicitation techniques. Lingua 16:1-19.

Dawkins, R.M. (1916). Modern Greek in Asia Minor. Cambridge: Cambridge University Press.

Guardiano, C. \& M. Stavrou. (2014). Greek and Romance in Southern Italy: history and contact in nominal structures. L'Italia Dialettale 75: 121-148.

Hatzidakis, G. (1892). Einleitung in die Neugriechische Grammatik. Leipzig: Breitkopf \& Härtel.

Heine, B. \& T. Kuteva (2005). Language contact and grammatical change. Cambridge: Cambridge University Press.

Höhn, Georg F.K. (2016). Unagreement is an illusion. Apparent person mismatches and nominal structure. Natural Language and Linguistic Theory 32: 543-592.

Joseph, B. (1983). The Synchrony and Diachrony of the Balkan Infinitive. A Study in Areal, General and Historical Linguistics. Cambridge: Cambridge University Press. 
Karatsareas, P. (2013). Understanding diachronic change in Cappadocian Greek: the dialectological perspective. Journal of Historical Linguistics 3: 192-229.

Kayne, R. (1996). Microparametric syntax: some introductory remarks. In J.R. Black \& V. Motapanyane (eds.), Microparametric syntax and dialect variation. Amsterdam: John Benjamins, 9-18.

Koeneman, O. \& M. Lekakou (2007). The role of syntactic theory in the SAND and EDiSyn projects. Ms. Meertens Institute.

Kontosopoulos, N. (1988). Glossikos atlas tis Kritis. Eisagoji ke dialektolojiki xartes [A linguistic atlas of Crete. Introduction and dialectological maps]. Heraklion: Panepistimiakes Ekdosis Kritis.

Kontosopoulos, N. (2004). Dialektoi ke idiomata tis Neas Ellinikis [Dialects and Idioms of Modern Greek]. Athens: Grigoris.

Ledgeway, A. (2013). Greek Disguised as Romance? The Case of Southern Italy. In M. Janse, B. Joseph, A. Ralli \& M. Bagriacik (eds.), Proceedings of the 5 th International Conference on Greek Dialects and Linguistic Theory. Patras: Laboratory of Modern Greek Dialects, University of Patras, 184-228.

Lekakou M., V. Baldissera \& A. Anastasopoulos (2013). Documentation and analysis of an endangered language: aspects of the grammar of Griko. University of Ioannina. URL: http://griko.project.uoi.gr/

Lekakou, M. \& P. Karatsareas (2016). Marking definiteness multiply: evidence from two varieties of Greek. Studies in Greek Linguistics 36: 189-204.

Lekakou, M. \& J. Quer (2016). Subjunctive mood in Griko: a microcomparative approach. Lingua 174: $65^{-85}$.

Liosis, N. (2017). Auxiliary verb constructions and clitic placement: evidence from Tsakonian. Journal of Greek Linguistics 17: 37-72.

Mavrogiorgos, M. (2010). Clitics in Greek: A Minimalist Account of Proclisis and Enclisis. Amsterdam: John Benjamins.

Michelioudakis, D. \& Sitaridou, I., (2016). Recasting the typology of multiple wh-fronting: Evidence from Pontic Greek. Glossa: a journal of general linguistics. 1(1), p. 40. DoI: http://doi.org/10.5334/gjgl.72

Newton, B. (1972). The generative interpretation of dialect: a study of Modern Greek phonology. Cambridge: Cambridge University Press.

Ralli, A. (2006). Syntactic and Morphosyntactic Dialectal Phenomena in Modern Greek: The State of the Art. Journal of Greek Linguistics 7: 121-159.

Rizzi, L. (1997). The fine structure of the left periphery. In L. Haegeman (ed.), Elements of Grammar: A Handbook in Generative Syntax. Dordrecht: Kluwer, 281-337.

Rohlfs, G. (1924). Griechen und Romanen in Unteritalien. Geneva: Olschki.

Roussou, A. (2000). On the left periphery: modal particles and complementisers. Journal of Greek Linguistics 1: 65-94.

Roussou, A. (2009). Complementizers in the Greek dialects. Studies in Greek Linguistics 29: $371-384$. 
Sitaridou, I. (2014). Modality, antiveridicality and complementation: the Romeyka infinitive as a negative polarity item. Lingua 148:118-146.

Thomason, S. \& T. Kaufman (1988). Language Contact, Creolization, and Genetic Linguistics. Berkeley/Los Angeles: University of California Press.

Trudgill, P. (2003). Modern Greek dialects: A preliminary classification. Journal of Greek Linguistics 4: 45-64.

Tzitzilis, C. (2000). Modern Greek dialects and Modern Greek dialectology [Neoellinikes dialekti ke neoelliniki dialektologia]. In Christidis 2000 (ed.), 168-174. 